\title{
Association of Antibiotic Resistance, Cell Adherence, and Biofilm Production with the Endemicity of Nosocomial Klebsiella pneumoniae
}

\author{
María Dolores Alcántar-Curiel (D), ${ }^{1}$ Carmen Alejandra Ledezma-Escalante, ${ }^{1,2}$ \\ Ma Dolores Jarillo-Quijada, ${ }^{1}$ Catalina Gayosso-Vázquez, ${ }^{1}$ Rayo Morfín-Otero $\mathbb{D}^{3}{ }^{3}$ \\ Eduardo Rodríguez-Noriega, ${ }^{3}$ María Lilia Cedillo-Ramírez, ${ }^{4}$ \\ José Ignacio Santos-Preciado $\left(\mathbb{D},{ }^{1}\right.$ and Jorge A. Girón ${ }^{4,5}$ \\ ${ }^{1}$ Laboratorio de Infectología, Microbiología e Inmunología Clínicas, Unidad de Investigación en Medicina Experimental, \\ Facultad de Medicina, Universidad Nacional Autónoma de México, Mexico City, Mexico \\ ${ }^{2}$ Departamento de Microbiología, Escuela Nacional de Ciencias Biológicas, Instituto Politécnico Nacional, Mexico City, Mexico \\ ${ }^{3}$ Departamento de Enfermedades Infecciosas, Hospital Civil de Guadalajara, Jalisco, Mexico \\ ${ }^{4}$ Centro de Detección Biomolecular, Benemérita Universidad Autónoma de Puebla, Puebla, Mexico \\ ${ }^{5}$ Department of Pediatrics, University of Virginia, Charlottesville, Virginia, USA
}

Correspondence should be addressed to María Dolores Alcántar-Curiel; alcantar@unam.mx

Received 17 May 2018; Accepted 31 July 2018; Published 23 September 2018

Academic Editor: Klaus P. Hunfeld

Copyright ( 2018 María Dolores Alcántar-Curiel et al. This is an open access article distributed under the Creative Commons Attribution License, which permits unrestricted use, distribution, and reproduction in any medium, provided the original work is properly cited.

\begin{abstract}
Klebsiella pneumoniae is a leading cause of multiple nosocomial infections, some of which are associated with high mortality. The increasing prevalence of antibiotic-resistant strains highlights their clinical importance and how complicated managing treatment can be. In this study, we investigated antimicrobial resistance, cell adherence, and biofilm production of nosocomial K. pneumoniae strains isolated from surveillance studies in a Mexican tertiary hospital and evaluated the potential association of these phenotypes with endemicity. The great majority of the clones exhibited adhesion to cultured epithelial cells and were strong biofilm producers. A direct relationship between adhesion phenotypes, biofilm production, and endemicity was not always apparent. Biofilm formation and production of ESBL did not appear to be directly associated. Notably, all the endemic strains were multidrug-resistant. This study emphasizes that while endemic strains possess various virulence-associated properties, antimicrobial resistance appears to be a determining factor of their endemicity.
\end{abstract}

\section{Introduction}

Klebsiella pneumoniae, a Gram-negative opportunistic pathogen, ranks among the most important causes of nosocomial infections in developing countries and among the eight most important causes in developed countries [1], especially in immunocompromised patients and those with indwelling medical devices on which this microorganism is able to grow in a biofilm. The main reservoir for transmission of $K$. pneumoniae is the gastrointestinal tract of patients and the hands of medical staff [2]. Nosocomial infections caused by $K$. pneumoniae resistant to multiple antibiotics have become an increasing public health concern. Several studies have reported hospital outbreaks due to isolates of $K$. pneumoniae resistant to third-generation cephalosporins, aminoglycosides, and quinolones [3]. The production of extended-spectrum beta-lactamases and other mechanisms of antibiotics resistance are favored by the constant horizontal transfer of antimicrobial resistance genes through mobile elements such as plasmids and transposons, which are essential factors for $K$. pneumoniae to survive in nosocomial environments [4]. 
Nosocomial infections are related to the elevated use of invasive techniques for diagnostic, as well as to invasive and therapeutic interventions, particularly when medical devices are introduced in different anatomical regions of patients. Microbiological studies show that bacteria, including $K$. pneumoniae grow attached on the surfaces of such devices and infected tissues, producing biofilms, in which bacteria persist for long periods of time in spite of antimicrobial therapy and the presence of an immune system. Bacterial biofilms also pose a risk for dissemination between patients and throughout the hospital [5].

An essential step in the colonization of tissues and development of infection is the adherence of bacteria to host cells through surface-associated fimbrial and nonfimbrial adhesins [6,7]. Fimbriae are extracellular fibrillar adhesive appendages comprised of thousands of protein subunits. K. pneumoniae produces different virulence factors involved in pathogenesis, including capsular polysaccharide, lipopolysaccharide, fimbriae, siderophores, and serum resistance [4]. K. pneumoniae strains express at least three different fimbrial types: mannose-sensitive type 1 fimbriae, mannose-resistant type 3 fimbriae, and the E. coli common pilus (ECP) [8-10]. All of these fimbriae are involved in the adherence of clinical K. pneumoniae isolates to host cells and in biofilm formation $[9,10]$.

While it appears that antibiotic resistance coupled to biofilm formation and extracellular fibrillar adhesive appendages have contributed to the global spread of $K$. pneumoniae and other gram-negative bacilli, the relationship among these factors has not been elucidated [11]. Recently, the relationship between virulence, multidrug resistance, and biofilm formation in clinical strains of Acinetobacter baumannii and K. pneumoniae was evaluated [11]. It was found that the ability to form biofilms was not associated with clonal types or multidrug resistance.

In this paper, we sought to investigate the virulenceassociated properties including antibiotic resistance, cell adherence, biofilm production, and endemicity of a collection of nosocomial K. pneumoniae strains isolated in a Mexican tertiary hospital [12]. Our data highlights the importance and need to further investigate the bacterial and host factors that contribute to the development of nosocomial infections and the prevalence of $K$. pneumoniae isolates in hospitalized patients, some of which are responsible for recurrent outbreaks.

\section{Materials and Methods}

2.1. Bacterial Isolates. A collection of $168 \mathrm{~K}$. pneumoniae strains isolated from patients who developed nosocomial infections while hospitalized in the Hospital Civil de Guadalajara during a 45-month period, from February 1999 to October 2002, was evaluated for adherence to tissue cultured cells, biofilm formation on plastic, antibiotic resistance profile, and endemicity. The strains correspond to a bank of nosocomial isolates, which are part of our laboratory bacterial collection. K. pneumoniae ATCC700603 was employed as a positive control for type 1 pili and type 3 pili production and biofilm formation, for cell adherence this strain was used as internal control, because its level of adherence is low. K. pneumoniae Kpnl and Escherichia coli K12 (HB101) were used as negative controls.

2.2. Antimicrobial Susceptibility. The minimum inhibitory concentrations (MICs) for amikacin, gentamicin, ampicillin, aztreonam, cefepime, cefotaxime, cefoxitine, ceftazidime, cefuroxime, ticarcillin-clavulanate, tobramycin, imipenem, ciprofloxacin, levofloxacin, ofloxacin, and tetracycline were determined using the Sensititre ARIS ${ }^{\circledR}$ 2X System (TREK Diagnostic Systems Inc., Westlake, Ohio, USA) and were confirmed using an agar dilution method, according to Clinical Laboratory Standards Institute (CLSI) guidelines [13]. In all multidrug-resistant strains, production of extended spectrum beta-lactamases (ESBLs), including ceftazidime and cefotaxime, was screened with or without clavulanate by the double disk synergism method [13]. K. pneumoniae ATCC 700603 and E. coli ATCC 25922 were used as positive and negative controls, respectively.

2.3. Genotyping by Pulsed-Field Gel Electrophoresis (PFGE). To determine the genetic relatedness of isolates, PFGE analysis was performed as previously described [14, 15]. Chromosomal DNA of K. pneumoniae isolates was prepared as described elsewhere [15]. DNA fragments were prepared by XbaI (New England Biolabs, Beverly, MA) restriction analysis and separated by PFGE using a GenePath System $\left(\right.$ Bio-Rad $\left.^{\circledR}\right)$. Restriction fragment analysis was used to define clonal related or unrelated isolates according to the Tenover criteria [16].

2.4. PCR Detection of Fimbrial Genes. The presence of type 1 pili, type 3 pili, and ECP ( $f i m A, m r k A$, and ecpA) major structural genes was determined by DNA amplification. fimA was amplified using primers fimA-F 5'CGG ACG GTA CGC TGT ATT TT-3' and fimA-R, 3'-GCT TCG GCG TTG TCT TTA TC-5', mrkA was amplified using primers G593, 5'CGG TAA AGT TAC CGA CGT ATC TTG TAC TG-3' and G594 3'GCT GTT AAC CAC ACC GGT GGT AAC 5', and ecpA was amplified using primers G569, 5'GCA ACA GCC AAA AAA GAC ACC-3' and G570, 3'-CCA GGT CGC GTC GAA CTG-5', as previously described [10]. A subset of amplified products was nucleotide sequenced and compared to pilin nucleotide sequences on the database GenBank. Additionally, strains producing type 1 pili were detected by the yeastagglutination assay. Briefly, $20 \mu \mathrm{L}$ of a 24 -h bacterial culture in Dulbecco's minimal essential medium (DMEM) containing high concentration of glucose was mixed with $20 \mu \mathrm{L}$ of a Saccharomyces cerevisiae suspension on a glass slide [17]. The presence of type 3 pili on the bacteria was evidenced by slide agglutination of tannic acid treated human erythrocytes (3\%) using $100 \mu \mathrm{L}$ of overnight bacterial cultures obtained in LB medium and DMEM high glucose [18].

2.5. Cell Adherence. The adherence assays were performed in quadruplicate employing human cervical HeLa cells seeded on 24-well polystyrene plates [18]. Three wells served to quantitate adhering bacteria and one well to visualize 
the adherence phenotypes by Giemsa staining and light microscopy. Briefly, cell monolayers at $80 \%$ confluence were infected with $10^{7}$ bacteria of overnight LB medium or DMEM cultures and incubated for $3 \mathrm{~h}$ at $37^{\circ} \mathrm{C}$ in a humidified atmosphere with $5 \% \mathrm{CO}_{2}$. The wells were washed two times with PBS (pH 7.4), treated with $0.1 \%$ Triton X-100, ten-fold serially diluted, and plated onto LB agar plates to quantitate the attached bacteria as colony-forming-units (CFUs). These experiments were performed in triplicate on 3 different days and the mean values were expressed as adhering CFUs. The data obtained were statistically analyzed using One-wayAnova and Tukey multiple comparison test and GraphPad Prism 7.04. A replica sample was fixed with $300 \mu \mathrm{L}$ of methanol, stained with Giemsa, and mounted on glass slides. The stained samples were visualized with a Nikon Eclipse microscope T 300-E.

2.6. Biofilm Production. Bacteria were grown statically in DMEM at $37^{\circ} \mathrm{C}$ during $3 \mathrm{~h}$ and adjusted to $1 \times 10^{10} \mathrm{CFU} / \mathrm{mL}$. The biofilm assay was performed in triplicate in 24-well polystyrene plates containing $400 \mu \mathrm{L}$ of DMEM with high glucose per well. One hundred $\mu \mathrm{L}$ of the bacteria was added to each well and incubated statically for $24 \mathrm{~h}$ at $37^{\circ} \mathrm{C}$. After washing $3 \mathrm{X}$ with PBS the biofilms formed were fixed with $1 \mathrm{~mL}$ of $2 \%$ formaldehyde for $20 \mathrm{~min}$, washed, and then stained with $0.5 \%$ Crystal Violet for $20 \mathrm{~min}$. The plates were washed exhaustively with distilled water and $1 \mathrm{~mL}$ of $95 \%$ ethanol was added to recover the absorbed stain. The dye was read in a spectrophotometer at $595 \mathrm{~nm}$ [10] and the values obtained were expressed as a biofilm production index (BPI). K. pneumoniae ATCC 700603 was used as a positive control with an assigned BPI value of 1.0 while E. coli K12 (HB101) was used as the negative control $(\mathrm{BPI}=0)$.

\section{Results}

3.1. Antimicrobial Susceptibility. Among the 168 K. pneumoniae isolates studied, $121(72.0 \%)$ were resistant to ceftazidime, $115(68.5 \%)$ to cefotaxime, $163(97 \%)$ to cefuroxime, 137 $(81.5 \%)$ to aztreonam, $125(74.4 \%)$ to gentamicin, and 113 $(67.2 \%)$ to amikacin. The $\mathrm{MIC}_{50}$ to cefotaxime and ceftazidime in these strains was $>128 \mu \mathrm{g} / \mathrm{mL}$ (Table 1). All ceftazidime and cefotaxime resistant isolates were positive for ESBL production. All isolates were susceptible to imipenem and $6 \%$ were resistant to ciprofloxacin.

3.2. Genotyping and Epidemiological Analysis. Among the 168 isolates, we found 59 different clones of which 23 of them (containing 127 isolates) were ESBL producers (Figure 1). Ceftazidime-resistant $\left(\mathrm{CAZ}^{\mathrm{R}}\right.$ ) clones G5 (27 isolates) and G9 (39 isolates) were responsible for $40 \%$ of the total nosocomial infections. The Department of Hospital Epidemiology at the Hospital Civil de Guadalajara reported 4 outbreaks of bacteremia due to K. pneumoniae during 2000-2002 (Figure 2). The first outbreak included 7 cases of bacteremia due to clone G9 in the Neonatal Intensive Care Unit 1 (NICU1) in August 2000. The second outbreak took place shortly thereafter in September 2000 in NICU2 involving 10 bacteremia cases due to clone G5. Isolates of both clones were detected for the first time in both NICU wards since the beginning of year 2000 but had been endemic for almost 8 months before they produced outbreaks. After these outbreaks, clones G5 and G9 were isolated in these wards and reported as endemic. A year and a half later (January/February 2002), clone G9 caused another outbreak involving 15 bacteremia cases in NICU2. At the same time a fourth outbreak occurred in NICU1 and in the General Pediatric ward, involving 10 bacteremia cases caused by a newly introduced clone G49. After this last outbreak and until the end of the study in October 2002 no nosocomial infections due $K p n C A Z^{\mathrm{R}}$ isolates were reported. In all, $25 \%$ of the 168 nosocomial infection cases caused by $K$. pneumoniae isolates were outbreak strains and $75 \%$ were considered endemic.

3.3. Detection of fimA, mrkA, and ecpA Genes. All of the 168 isolates tested agglutinated yeast cells indicating they all produce type 1 pili. However, only $78 \%$ (131) were positive for the presence of fimA gene. This result is not surprising since the fim $A$ gene is subject to antigenic and phase variation leading to On and Off states of piliation. Although 100\% of the studied isolates carried the $m r k A$ gene, only $66 \%$ (111) of them produced type pili 3 as determined by phenotypic tests. Regarding the frequency of the ECP, 91\% (153/168) of the isolates contained the ecpA gene. These data indicate that 3 fimbrial types are highly conserved among the Klebsiellae and that they must be important for the biology of these organisms.

3.4. Cell Adherence. To evaluate the adhesiveness of the $K$. pneumoniae strains to HeLa cell monolayers, a representative isolate of each of the 59 clones was randomly selected. Based on the level of adherence the strains were classified as follows: highly adherent $\left(>1 \times 10^{7} \mathrm{CFU} /\right.$ well), moderately adherent (1$9 \times 10^{6} \mathrm{CFU} /$ well), and poorly adherent $\left(<1 \times 10^{5} \mathrm{CFU} /\right.$ well). Notably, $100 \%$ of these clones were PCR positive for type 3 pili genes while the presence of ECP and type 1 pili genes varied between $80-91 \%$ and $60-70 \%$, respectively. We found that only $5 / 59(8.5 \%)$ of the clones were highly adherent (Table 2, Figure 3) while the great majority of the clones $48 / 59(81.4 \%)$ exhibited moderate adhesion to HeLa cells (Table 2, Figure 3). The remaining 6 clones $(10.2 \%)$ were poorly adherent (Table 2, Figure 3). In sum, $91 \%$ of the clones studied were moderately to highly adherent to HeLa cells and possessed the 3 fimbrial genes to different extent. Because clones 5 and 9 were the most prevalent, we analyzed whether there was a significant difference in adherence between the strains of the same clone. Three representative strains of each of these two clones were selected for this analysis. Isolates 591, 097/01, and 588 of clone 5 and isolates 277/01, 373, and 821 of clone 9 exhibited moderate adherence, suggesting that this phenotype is an important attribute of these strains.

3.5. Biofilm Production. Sixty-nine percent (41/59) of the clones were strong biofilm producers and showed a BPI $>1$, $20.3 \%(12 / 59)$ were weak biofilm producers (BPI $<1)$, and $10.1 \%(6 / 59)$ did not produce biofilm (BPI =0) $($ Table 2$)$. 
TABLE 1: Antibiotic resistance phenotype of the $168 \mathrm{~K}$. pneumoniae nosocomial isolates.

\begin{tabular}{|c|c|c|c|}
\hline Antibiotic & \% Resistance $(n)$ & $\mathrm{MIC}_{50}(\mu \mathrm{g} / \mathrm{ml})$ & $\mathrm{MIC}_{90}(\mu \mathrm{g} / \mathrm{ml})$ \\
\hline AMK & $67.2 \%(113)$ & 64 & $>128$ \\
\hline AMP & $100 \%(168)$ & 32 & $>128$ \\
\hline ATM & $81.5 \%(137)$ & $>128$ & $>128$ \\
\hline FEP & $8.9 \%(15)$ & 8.0 & 16 \\
\hline CTX & $68.5 \%(115)$ & $>128$ & $>128$ \\
\hline FOX & $4.1 \%(7)$ & 8.0 & 16 \\
\hline CAZ & $72.0 \%(121)$ & $>128$ & $>128$ \\
\hline CXM & $97.0 \%(163)$ & $>8.0$ & $>8.0$ \\
\hline CIP & $6.5 \%(11)$ & 0.125 & 1.0 \\
\hline GEN & $74.4 \%(125)$ & $>128$ & $>128$ \\
\hline IPM & $0 \%(0)$ & 1.0 & 2.0 \\
\hline LVX & $7.1 \%(12)$ & 0.5 & 2.0 \\
\hline OFX & $3.5 \%(6)$ & 0.25 & 1.0 \\
\hline TET & $83.9 \%(141)$ & 64 & 64 \\
\hline TOB & $54.1 \%(91)$ & 64 & 64 \\
\hline TIM & $36.3 \%(61)$ & $16 / 2$ & $>256 / 2$ \\
\hline
\end{tabular}

AMK, amikacin; AMP, ampicillin; ATM, aztreonam; FEP, cefepime; CTX, cefotaxime; FOX, cefoxitin; CAZ, ceftazidime; CXM, cefuroxime; CIP, ciprofloxacin; GEN, gentamicin; IPM, imipenem; LVX, levofloxacin; OFX, ofloxacin; TET, tetracycline; TIM, ticarcillin-clavulanic acid; TOB, tobramycin.

TABLE 2: Adherence phenotype, biofilm formation, multidrug resistance phenotype and endemicity of 59 nosocomial clones of K. pneumoniae strains.

\begin{tabular}{|c|c|c|c|c|}
\hline Clone/number of isolates & $\begin{array}{c}\text { Adherence } \\
\text { phenotype }(n)\end{array}$ & $\mathrm{BPI}(n)$ & $\begin{array}{c}\text { MDR } \\
\text { phenotype }(n)\end{array}$ & Endemicity $(n)$ \\
\hline $\mathrm{G} 2 / 2, \mathrm{G} 11 / 2, \mathrm{G} 39 / 1, \mathrm{G} 44 / 1, \mathrm{G} 45 / 1$ & High (5) & $\begin{array}{l}>1(4) \\
<1(1)\end{array}$ & Negative (5) & Non endemic (5) \\
\hline $\begin{array}{l}\mathrm{G} 1 / 14, \mathrm{G} 3 / 2, \mathrm{G} 5 / 27, \mathrm{G} 6 / 4, \mathrm{G} 7 / 8, \mathrm{G} 8 / 1, \mathrm{G} 9 / 39 /, \mathrm{G} 10 / 1, \\
\mathrm{G} 12 / 2, \mathrm{G} 13 / 1, \mathrm{G} 14 / 1, \mathrm{G} 16 / 2, \mathrm{G} 17 / 1, \mathrm{G} 18 / 1, \mathrm{G} 19 / 1, \mathrm{G} 20 / 1, \\
\mathrm{G} 21 / 1, \mathrm{G} 23 / 1, \mathrm{G} 24 / 2, \mathrm{G} 25 / 1, \mathrm{G} 26 / 1, \mathrm{G} 28 / 1, \mathrm{G} 30 / 1, \mathrm{G} 31 / 1, \\
\mathrm{G} 32 / 1, \mathrm{G} 33 / 2, \mathrm{G} 34 / 1, \mathrm{G} 35 / 1, \mathrm{G} 36 / 1, \mathrm{G} 37 / 1, \mathrm{G} 38 / 1, \mathrm{G} 40 / 2, \\
\mathrm{G} 41 / 1, \mathrm{G} 42 / 1, \mathrm{G} 43 / 1, \mathrm{G} 46 / 1, \mathrm{G} 48 / 1, \mathrm{G} 49 / 1, \mathrm{G} 50 / 1, \mathrm{G} 51 / 1, \\
\mathrm{G} 52 / 1, \mathrm{G} 53 / 1, \mathrm{G} 54 / 1, \mathrm{G} 55 / 1, \mathrm{G} 56 / 1, \mathrm{G} 57 / 1, \mathrm{G} 58 / 1, \mathrm{G} 5 / 1\end{array}$ & Moderate (48) & $\begin{array}{c}>1(35) \\
<1(9) \\
0(4)\end{array}$ & $\begin{array}{l}\text { Positive (23) } \\
\text { Negative (25) }\end{array}$ & $\begin{array}{c}\text { Endemic (6) } \\
\text { Non endemic (42) }\end{array}$ \\
\hline $\mathrm{G} 4 / 1, \mathrm{G} 22 / 4, \mathrm{G} 47 / 2, \mathrm{G} 27 / 1, \mathrm{G} 29 / 1, \mathrm{G} 15 / 1$ & Poor (6) & $\begin{array}{l}>1(3) \\
<1(2) \\
0(1)\end{array}$ & $\begin{array}{l}\text { Positive (5) } \\
\text { Negative (1) }\end{array}$ & Non endemic (6) \\
\hline
\end{tabular}

$\mathrm{BPI}=$ Biofilm production index. $\mathrm{MDR}=$ multidrug resistance. See text for description of adherence phenotypes.

3.6. Correlation between Adherence, Biofilm Production, Antimicrobial Resistance, and Endemicity of K. pneumoniae Clones. Most of the highly adherent clones had a BPI $>1$ while the vast majority ( 35 clones) of the moderately adherent clones had BPI $>1,9$ clones had a BPI $<1$, and 4 clones were nonbiofilm producers $(\mathrm{BPI}=0)$. Among the poorly adherent clones 3,2 , and 1 had BPIs $>1,<1$ or 0 , respectively (Table 2).

The most frequent clones with the greatest periods of endemicity were clones 1, 5, 7, 9, and 49 (Figure 2). Clone 9, which had the greatest period of endemicity (24 months), contained the largest number of isolates (Figure 2, Table 3). Among isolates of clone 9, the great majority $(61.5 \%)$ were weak biofilm producers (BPI <1),
$10.2 \%$ were strong biofilm producers (BPI $>1$ ), and a significant percentage of the isolates (28.2\%) were nonbiofilm producers (BPI $=0)$ (Table 3$)$. Interestingly, all of the isolates belonging to clone 9 were resistant to ceftazidime.

Clone 5, the second most frequent clone, had a 10-month period of endemicity (Figure 2, Table 3 ) and showed a high level of adherence to HeLa cells. The first group of isolates of clone 5 obtained during the first four months showed a BPI $<1$, while the second group of isolates obtained over the next five months had a BPI $>1$ (Table 3 ). All isolates belonging to this clone were resistant to ceftazidime.

Clones 1, 7, and 49 persisted for 23, 18, and 10 months in the hospital environment, respectively (Figure 2, Table 3). 


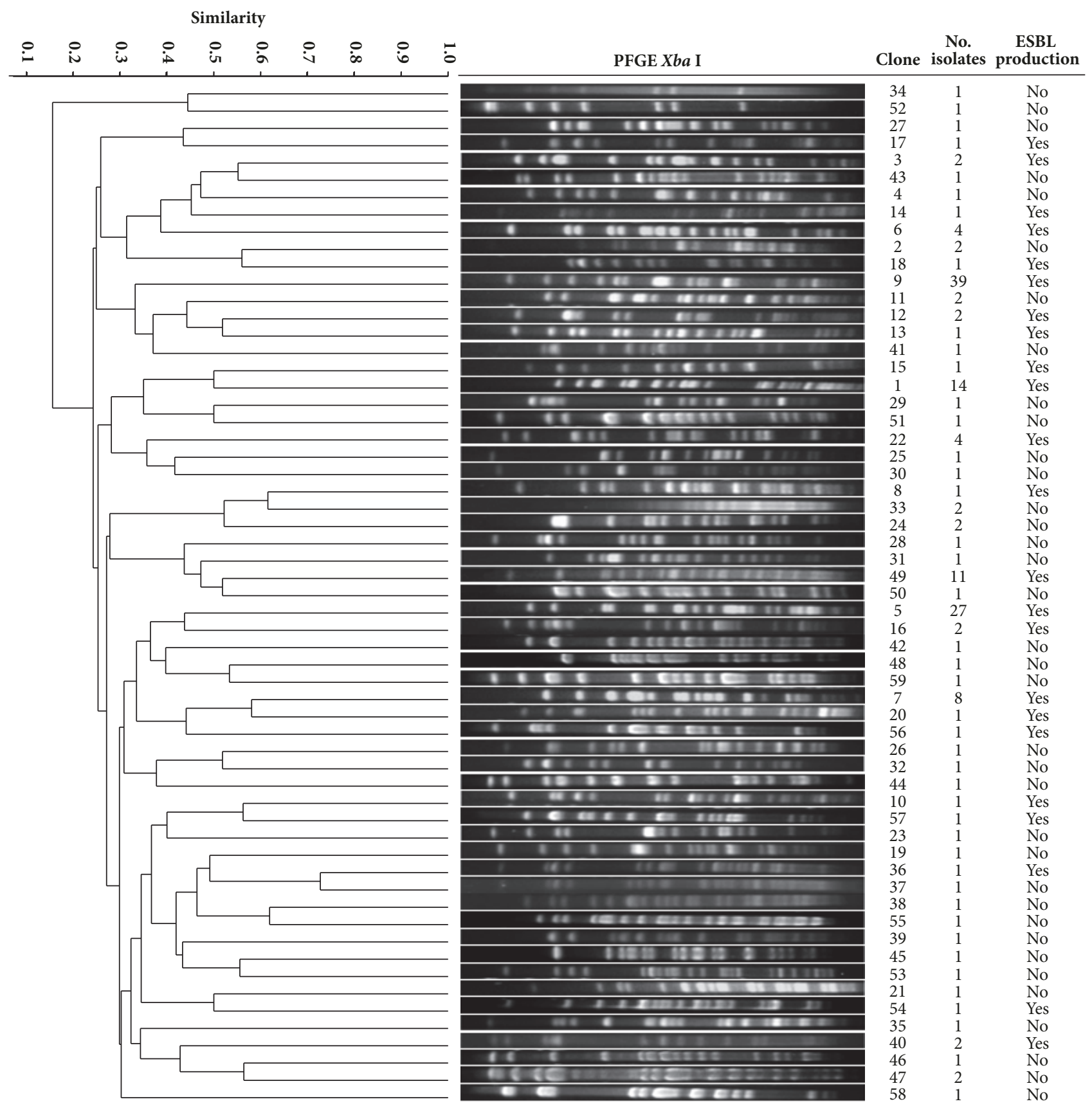

FIGURE 1: Dendrogram representing genetic relationships among $168 \mathrm{~K}$. pneumoniae strains. One representative strain of each PFGE pattern (clone) identified is presented. ESBL-producing K. pneumoniae were part of 23 different PFGE patterns.

Interestingly, although these clones exhibited moderate cell adhesion, they showed a BPI $>1$ and were all resistant to ceftazidime (Table 3).

Clones 11, 24, and 47 showed a significant increase in BPI from the first to the second isolation. In addition, one isolate from clone 47 was sensitive to ceftazidime, while the second isolate was ceftazidime-resistant. In contrast, the first isolate of clone 22 was a strong biofilm producer (BPI $>1$ ) but the next consecutive four isolates had a BPI $<1$. The remaining 50 clones were comprised of 1 or 2 isolates, of which $59 \%$ showed high biofilm production and, of these, $77 \%$ were sensitive to ceftazidime (Table 2).

\section{Discussion}

In the last decade, $K$. pneumoniae has emerged among the 5 most important pathogens causing nosocomial infections in Mexico [12], and as one of the most prevalent ESBLproducing isolates in a tertiary care teaching hospital in Guadalajara, Jalisco, Mexico [12]. This motivated us to study 


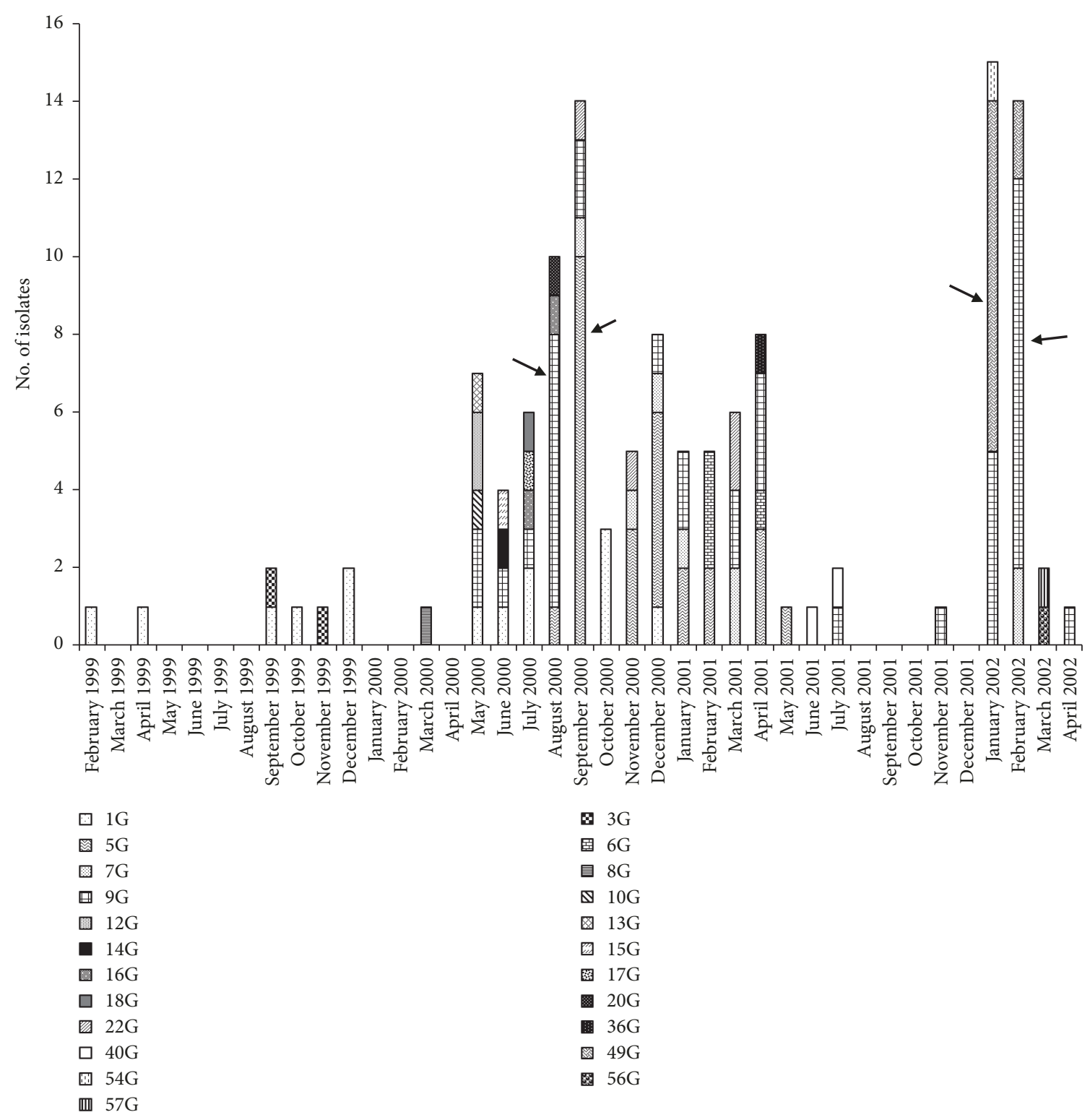

Figure 2: ESBL-producing K. pneumoniae clones identified during a 45-month surveillance study period. A total of 23 clones were detected in 127 ESBL-producing K. pneumoniae strains. Arrows show four different outbreaks of bacteremia caused by K. pneumoniae.

antimicrobial resistance, clonality, endemicity, and other virulence properties of the strains responsible for several outbreaks in this setting. Our study strongly suggests that antimicrobial resistance plays a crucial role in the persistence of $K$. pneumoniae in the hospital environment. This notion is based on the finding that a significant percentage $39 \%$ of the clones (23/59) produced ESBL, of which clones 5 and 9 caused major outbreaks in two years, and were designated as endemic clones. These data are consistent with the outcome of other recent studies in which K. pneumoniae and other ESBLproducing enterobacterial strains from cases of nosocomial infections were reported $[12,19-21]$.

In addition to antimicrobial resistance, cell adhesion and biofilm formation are other attributes that have been extensively studied and have been linked to the virulence and persistence of K. pneumoniae in the hospital environment. Adherence is the first step in host colonization and in the formation of biofilms. The adherence of $K$. pneumoniae is mediated by multiple fimbrial types [10]. We studied the relationship between the ability of these isolates to adhere to HeLa cells and the production of type 1 , type 3 pili, and ECP. We found that all isolates had the $m r k A$ type 3 pili gene and the majority of strains $(\sim 78 \%)$ contained fimA, regardless of their level of cell adherence. ECP was identified in 91\% and $80 \%$ of the isolates showing moderate and high levels of adherence, respectively. Type 3 pili and ECP appears tightly associated with the adhesion properties of $K$. pneumoniae, a finding consistent with previous studies [10, 22]. These data indicate that these 3 fimbrial types are highly conserved among nosocomial $K$. pneumoniae and that they must be 
TABLE 3: K. pneumoniae belonging to the five most frequent and endemic clones and phenotype of biofilm production.

\begin{tabular}{|c|c|c|c|c|c|c|c|c|c|c|c|}
\hline $\begin{array}{l}\text { Isolate } \\
\text { number }\end{array}$ & Isolation date & Clone & $\begin{array}{l}\text { Biofim } \\
\text { Produc- } \\
\text { tion Index } \\
\text { (OD) }\end{array}$ & $\begin{array}{l}\text { Isolate } \\
\text { number }\end{array}$ & $\begin{array}{l}\text { Isolation } \\
\text { date }\end{array}$ & Clone & $\begin{array}{c}\text { Biofim } \\
\text { Produc- } \\
\text { tion index } \\
(\mathrm{OD})\end{array}$ & $\begin{array}{l}\text { Isolate } \\
\text { number }\end{array}$ & $\begin{array}{c}\text { Isolation } \\
\text { date }\end{array}$ & Clone & $\begin{array}{c}\text { Biofim } \\
\text { Produc- } \\
\text { tion index } \\
(\mathrm{OD})\end{array}$ \\
\hline 316 & 02/24/1999 & G1 & 2.0 & 794 & 01/08/2001 & G5 & 1.4 & 908 & $03 / 09 / 2001$ & G9 & 0.1 \\
\hline 319 & 04/28/1999 & G1 & 1.7 & 796 & 01/09/2001 & G5 & 1.6 & 931 & $04 / 05 / 2001$ & G9 & 0.1 \\
\hline 323 & 09/14/1999 & G1 & 1.7 & 823 & 02/10/2001 & G5 & 1.5 & 932 & $04 / 09 / 2001$ & G9 & 0.1 \\
\hline 325 & $10 / 27 / 1999$ & G1 & 2.1 & 828 & 02/16/2001 & G5 & 1.3 & $96 / 01$ & $04 / 09 / 2001$ & G9 & 0.1 \\
\hline 328 & $12 / 15 / 1999$ & G1 & 1.7 & $100 / 01$ & $04 / 04 / 2001$ & G5 & 1.5 & $120 / 01$ & $07 / 18 / 2001$ & G9 & 0.2 \\
\hline 329 & $12 / 15 / 1999$ & G1 & 1.7 & $99 / 01$ & $04 / 04 / 2001$ & G5 & 1.4 & $293 / 01$ & $11 / 22 / 2000$ & G9 & 0.1 \\
\hline 365 & 05/19/2000 & G1 & 1.5 & $97 / 01$ & 04/10/2001 & G5 & 0.2 & $262 / 01$ & $01 / 03 / 2002$ & G9 & 0.2 \\
\hline 471 & $06 / 29 / 2000$ & G1 & 1.6 & $107 / 01$ & 05/10/2001 & G5 & 1.5 & $261 / 01$ & $01 / 14 / 2002$ & G9 & 0.6 \\
\hline 469 & 07/14/2000 & G1 & 1.4 & 601 & 09/25/2000 & G7 & 1.4 & $265 / 01$ & $01 / 17 / 2002$ & G9 & 0.1 \\
\hline 472 & $07 / 17 / 2000$ & G1 & 1.3 & 816 & $11 / 26 / 2000$ & G7 & 3.5 & $266 / 01$ & $01 / 17 / 2002$ & G9 & 2.1 \\
\hline 604 & $10 / 03 / 2000$ & G1 & 2.0 & 818 & $12 / 28 / 2000$ & G7 & 1.4 & $277 / 01$ & $01 / 30 / 2002$ & G9 & 0.3 \\
\hline 605 & $10 / 04 / 2000$ & G1 & 2.1 & 899 & 01/17/2001 & G7 & 3.5 & $281 / 01$ & $02 / 02 / 2002$ & G9 & 0.7 \\
\hline 606 & $10 / 10 / 2000$ & G1 & 1.2 & 826 & 03/01/2001 & G7 & 3.8 & $282 / 01$ & $02 / 04 / 2002$ & G9 & 0.3 \\
\hline 817 & $12 / 08 / 2000$ & G1 & 1.8 & 902 & $02 / 02 / 2001$ & G7 & 3.0 & $288 / 01$ & $02 / 06 / 2002$ & G9 & 0.1 \\
\hline 588 & $08 / 22 / 2000$ & G5 & 1.1 & $369 / 01$ & $02 / 11 / 2002$ & G7 & 0.9 & $289 / 01$ & $02 / 06 / 2002$ & G9 & 0.2 \\
\hline 591 & 09/10/2000 & G5 & 0.9 & $393 / 01$ & $02 / 11 / 2002$ & G7 & 1.6 & $364 / 01$ & $02 / 06 / 2002$ & G9 & 0.3 \\
\hline 592 & 09/12/2000 & G5 & 1.1 & 373 & 05/03/2000 & G9 & 1.4 & $292 / 01$ & $02 / 10 / 2002$ & G9 & 0.1 \\
\hline 593 & 09/12/2000 & G5 & 0.7 & 372 & $05 / 06 / 2000$ & G9 & 0 & $366 / 01$ & $02 / 11 / 2002$ & G9 & 0 \\
\hline 594 & 09/14/2000 & G5 & 0.8 & 466 & $06 / 28 / 2000$ & G9 & 0 & $370 / 01$ & $02 / 12 / 2002$ & G9 & 0 \\
\hline 596 & $09 / 22 / 2000$ & G5 & 0.6 & 467 & 07/14/2000 & G9 & 0 & $365 / 01$ & $02 / 12 / 2002$ & G9 & 2.0 \\
\hline 597 & $09 / 22 / 2000$ & G5 & 0.7 & 522 & 08/02/2000 & G9 & 0.2 & $392 / 01$ & $02 / 12 / 2002$ & G9 & 0 \\
\hline 598 & $09 / 22 / 2000$ & G5 & 0.8 & 516 & $08 / 03 / 2000$ & G9 & 0.3 & $400 / 01$ & $04 / 02 / 2002$ & G9 & 0.3 \\
\hline 599 & $09 / 22 / 2000$ & G5 & 0.5 & 517 & $08 / 04 / 2000$ & G9 & 0.3 & $267 / 01$ & $01 / 23 / 2002$ & G49 & 2.4 \\
\hline 835 & $09 / 22 / 2000$ & G5 & 0.3 & 519 & $08 / 06 / 2000$ & G9 & 0 & $272 / 01$ & $01 / 25 / 2002$ & G49 & 2.1 \\
\hline 602 & $09 / 25 / 2000$ & G5 & 0.5 & 586 & 08/97/2000 & G9 & 0 & $276 / 01$ & $01 / 25 / 2002$ & G49 & 0.9 \\
\hline 815 & $11 / 13 / 2000$ & G5 & 0.6 & 523 & 08/10/2000 & G9 & 1.0 & $358 / 01$ & $01 / 26 / 2002$ & G49 & 2.2 \\
\hline 814 & $11 / 14 / 2000$ & G5 & 0.7 & 526 & $08 / 25 / 2000$ & G9 & 0 & $279 / 01$ & $01 / 30 / 2002$ & G49 & 1.3 \\
\hline 607 & $11 / 20 / 2000$ & G5 & 0.6 & 600 & $09 / 22 / 2000$ & G9 & 0.1 & $280 / 01$ & $01 / 30 / 2002$ & G49 & 1.4 \\
\hline 788 & $12 / 13 / 2000$ & G5 & 1.7 & 603 & $09 / 28 / 2000$ & G9 & 0.2 & $360 / 01$ & $01 / 30 / 2002$ & G49 & 2.4 \\
\hline 789 & $12 / 23 / 2000$ & G5 & 1.8 & 813 & $12 / 06 / 2000$ & G9 & 0 & $361 / 01$ & $01 / 31 / 2002$ & G49 & 2.1 \\
\hline 790 & $12 / 25 / 2000$ & G5 & 2.0 & 821 & 01/18/2001 & G9 & 0.2 & $284 / 01$ & $02 / 01 / 2002$ & G49 & 1.0 \\
\hline 791 & $12 / 25 / 2000$ & G5 & 2.2 & 901 & $01 / 24 / 2001$ & G9 & 0 & $285 / 01$ & $02 / 01 / 2002$ & G49 & 1.5 \\
\hline 793 & $12 / 25 / 2000$ & G5 & 1.6 & 906 & 03/02/2001 & G9 & 0.2 & $283 / 01$ & $10 / 01 / 2002$ & G49 & 0.8 \\
\hline
\end{tabular}

$\mathrm{BPI}>1=$ strong biofilm producer. $\mathrm{BPI}<1=$ weak biofilm producer. $\mathrm{BPI}=0$ non-biofilm producer.

important for the biology of these organisms and in their interaction with their human host.

Since there is an association between cell adherence and biofilm development, we expected that the manifestation of these phenotypes was directly related among the 168 isolates tested however, this was not the case. This can be explained by the fact that cell adherence and biofilm formation on nonbiological surfaces can be mediated by similar or different bacterial adherence factors, induced by host cell factors not present on abiotic surfaces, and by the intrinsic nature of epithelial cells compared to glass or plastic surfaces.
Another observation from this study is that the formation of biofilms and production of ESBL are not directly associated. For example, endemic clones 1, 5, 7, and 49 produced ESBL and formed high levels of biofilm. In contrast, endemic clone 9 clone was ESBL producer but was only a moderate biofilm producer. Most interesting and intriguing was to find that nonendemic clones produced strong biofilms independent of ESBL production. In agreement with our results are the recent observations by de Campos et al., [11] who did not find a link between antimicrobial resistance and biofilm production in clinical isolates of $K$. 


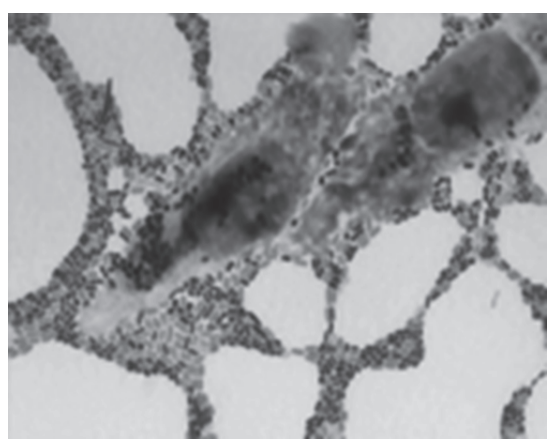

(a)

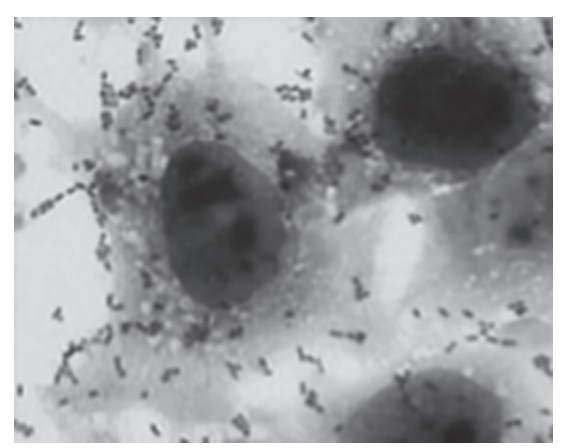

(b)

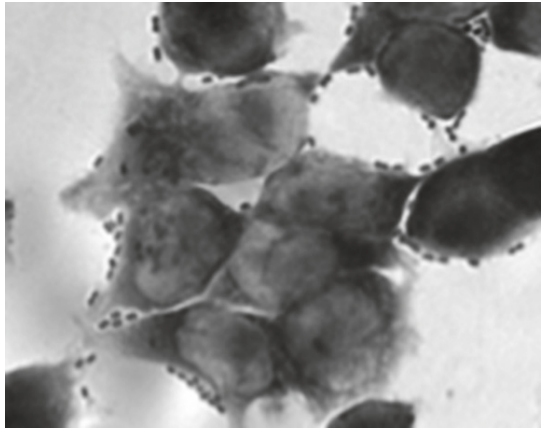

(c)

Figure 3: HeLa cell adherence phenotypes exhibited by K. pneumoniae strains. The collection of K. pneumoniae strains was tested for adherence to HeLa cells and we identified 3 levels of adherence: high, moderate, and poor. These micrographs were obtained after staining of the infected monolayers with Giemsa solution and visualize using light microscopy. Images were taken at 63X. (a) K. pneumoniae 232/01 (clone 47) showing high level of cell adherence with bacterial aggregates between neighboring cells. (b) K. pneumoniae 821 (clone 9) adheres moderately to the cells and (c) K. pneumoniae 373 (clone 4) adheres poorly.

pneumoniae and A. baumannii. However, our results contrast with other previous studies in which a direct relationship between the antimicrobial resistance and biofilm production has been shown [23-25]. These authors base their argument on the fact that under antibiotic pressure, mostly with a subinhibitory concentration of antimicrobials such as cefotaxime, biofilm formation was enhanced [25]. Alternatively, others workers have proposed that some plasmidencoded resistance genes such as ampR, [26], modulate fimbrial gene expression, and consequently biofilm formation.

Among all the isolates belonging to each of the five clones with the highest endemicity rates in this study, multidrug resistance was the factor which was always intrinsically associated among them. However, while cellular adhesion and the ability to form biofilms may contribute to the persistence of these pathogens in patients and in the environment, these factors were not always detected in K. pneumoniae endemic isolates.

Finally, our data underscores the importance of conserving nosocomial isolates in preserved culture collections so that as new technologies are developed we can further investigate the bacterial and host factors that contribute to the natural history of $K$. pneumoniae nosocomial infections, their prevalence in hospitalized patients, and in particular those responsible for recurrent outbreaks.

\section{Conclusions}

Currently, K. pneumoniae has reached high levels of endemicity in hospitals and is one of the main causes of nosocomial outbreaks. The results on our study show that the nosocomial K. pneumoniae strains analyzed were found to be heterogeneous in nature and their endemicity can be largely attributed to their multidrug-resistance. This study emphasizes that while endemic strains possess various virulenceassociated properties, antimicrobial resistance appears to be the determining factor of their endemicity.

\section{Data Availability}

The data used to support the findings of this study are included within the article.

\section{Conflicts of Interest}

The authors declare no conflicts of interest.

\section{Acknowledgments}

This work was supported by Consejo Nacional de Ciencia y Tecnología, México (Grant no. CB-104804-M), to María Dolores Alcántar Curiel. The authors are grateful to José Luis Fernández-Vázquez from the Universidad Nacional Autónoma de México, Ciudad de México, for his technical assistance on the PCR assays and to Marco Elias Gudiño Zayas from the Universidad Nacional Autónoma de México, Ciudad de México, for his assistance with the graphic design.

\section{References}

[1] H. A. Khan, A. Ahmad, and R. Mehboob, "Nosocomial infections and their control strategies," Asian Pacific Journal of Tropical Biomedicine, vol. 5, no. 7, pp. 509-514, 2015.

[2] E. Calbo, N. Freixas, M. Xercavins et al., "Foodborne nosocomial outbreak of SHV1 and CTX-M-15-producing Klebsiella pneumoniae: Epidemiology and control," Clinical Infectious Diseases, vol. 52, no. 6, pp. 743-749, 2011.

[3] O. E. Apondi, O. C. Oduor, B. K. Gye, and M. K. Kipkoech, "High prevalence of multi-drug resistant Klebsiella Pneumoniae in a tertiary teaching hospital in Western Kenya," African Journal of Infectious Diseases, vol. 10, no. 2, pp. 89-95, 2016.

[4] D. Alcantar-Curiel, J. C. Tinoco, C. Gayosso et al., "Nosocomial bacteremia and urinary tract infections caused by extendedspectrum $\beta$-lactamase-producing Klebsiella pneumoniae with plasmids carrying both SHV-5 and TLA-1 genes," Clinical Infectious Diseases, vol. 38, no. 8, pp. 1067-1074, 2004. 
[5] S. L. Percival, L. Suleman, and G. Donelli, "HealthcareAssociated infections, medical devices and biofilms: Risk, tolerance and control," Journal of Medical Microbiology, vol. 64, no. 4, pp. 323-334, 2015.

[6] R. Podschun and U. Ullmann, "Klebsiella spp. as nosocomial pathogens: epidemiology, taxonomy, typing methods, and pathogenicity factors," Clinical Microbiology Reviews, vol. 11, no. 4, pp. 589-603, 1998.

[7] J. W. Wilson, M. J. Schurr, C. L. LeBlanc, R. Ramamurthy, K. L. Buchanan, and C. A. Nickerson, "Mechanisms of bacterial pathogenicity," Postgraduate Medical Journal, vol. 78, no. 918, pp. 216-224, 2002.

[8] C.-L. Y. Ong, S. A. Beatson, M. Totsika, C. Forestier, A. G. McEwan, and M. A. Schembri, "Molecular analysis of type 3 fimbrial genes from Escherichia coli, Klebsiella and Citrobacter species," BMC Microbiology, vol. 10, no. 183, 2010.

[9] M. A. Schembri, J. Blom, K. A. Krogfelt, and P. Klemm, "Capsule and fimbria interaction in Klebsiella pneumoniae," Infection and Immunity, vol. 73, no. 8, pp. 4626-4633, 2005.

[10] M. D. Alcántar-Curiel, D. Blackburn, Z. Saldaña et al., "Multifunctional analysis of Klebsiella Pneumoniae fimbrial types in adherence and biofilm formation," Virulence, vol. 4, no. 2, pp. 129-138, 2013.

[11] P. A. de Campos, S. Royer, D. W. da Fonseca Batistão et al., "Multidrug Resistance Related to Biofilm Formation in Acinetobacter baumannii and Klebsiella pneumoniae Clinical Strains from Different Pulsotypes," Current Microbiology, vol. 72, no. 5, pp. 617-627, 2016.

[12] R. Morfín-Otero, M. D. Alcántar-Curiel, M. J. Rocha et al., "Acinetobacter baumannii infections in a tertiary care hospital in mexico over the past 13 years," Chemotherapy, vol. 59, no. 1, pp. 57-65, 2013.

[13] CLSI, Performance Standards for Antimicrobial Susceptibility Testing: Twenty-Five Informational Supplement, CLSI document M100-S25 Wayne (Clinical and Laboratory Standards Institute), PA, USA, 2015.

[14] G. Martínez-Aguilar, C. M. Alpuche-Aranda, C. Anaya et al., "Outbreak of Nosocomial Sepsis and Pneumonia in a Newborn Intensive Care Unit by Multiresistant Extended-Spectrum $\beta$ Lactamase-Producing Klebsiella pneumoniae High Impact on Mortality," Infection Control and Hospital Epidemiology, vol. 22, no. 11, pp. 725-728, 2001.

[15] G. Miranda, C. Kelly, F. Solorzano, B. Leanos, R. Coria, and J. E. Patterson, "Use of pulsed-field gel electrophoresis typing to study an outbreak of infection due to Serratia marcescens in a neonatal intensive care unit," Journal of Clinical Microbiology, vol. 34, no. 12, pp. 3138-3141, 1996.

[16] F. C. Tenover, R. D. Arbeit, and R. V. Goering, "Interpreting chromosomal DNA restriction patterns produced by pulsedfield gel electrophoresis: criteria for bacterial strain typing," Journal of Clinical Microbiology, vol. 33, no. 9, pp. 2233-2239, 1995.

[17] K. Melican, R. M. Sandoval, A. Kader et al., "Uropathogenic escherichia coli $\mathrm{P}$ and type 1 fimbriae act in synergy in a living host to facilitate renal colonization leading to nephron obstruction," PLoS Pathogens, vol. 7, no. 2, Article ID e1001298, 2011.

[18] Z. Saldaña, A. L. Erdem, S. Schüller et al., “The Escherichia coli common pilus and the bundle-forming pilus act in concert during the formation of localized adherence by enteropathogenic $\mathrm{E}$. coli," Journal of Bacteriology, vol. 191, no. 11, pp. 3451-3461, 2009.
[19] G. A. Jacoby and P. Han, "Detection of extended-spectrum $\beta$-lactamases in clinical isolates of Klebsiella pneumoniae and Escherichia coli," Journal of Clinical Microbiology, vol. 34, no. 4, pp. 908-911, 1996.

[20] M. Navarro-Navarro, R. E. Robles-Zepeda, A. Garibay-Escobar, and E. Ruiz-Bustos, "Hospital and community-acquired $\beta$ lactamases-producing Escherichia coli and Klebsiella pneumoniae at hospitals in Hermosillo, Sonora," Salud Pública de México, vol. 53, no. 4, pp. 341-344, 2011.

[21] P. L. Ho, Y. Y. Cheung, Y. Wang et al., "Characterization of carbapenem-resistant Escherichia coli and Klebsiella pneumoniae from a healthcare region in Hong Kong," European Journal of Clinical Microbiology \& Infectious Diseases, vol. 35, no. 3, pp. 379-385, 2016.

[22] P. Di Martino, N. Cafferini, B. Joly, and A. Darfeuille-Michaud, "Klebsiella pneumoniae type 3 pili facilitate adherence and biofilm formation on abiotic surfaces," Research in Microbiology, vol. 154, no. 1, pp. 9-16, 2003.

[23] R. Rao, R. Karthika, S. Singh et al., "Correlation between biofilm production and multiple drug resistance in imipenem resistant clinical isolates of Acinetobacter baumannii," Indian Journal of Medical Microbiology, vol. 26, no. 4, pp. 333-337, 2008.

[24] H.-W. Lee, Y. M. Koh, and J. Kim, "Capacity of multidrugresistant clinical isolates of Acinetobacter baumannii to form biofilm and adhere to epithelial cell surfaces," Clinical Microbiology and Infection, vol. 14, no. 1, pp. 49-54, 2008.

[25] C. Vuotto, F. Longo, M. Balice, G. Donelli, and P. Varaldo, "Antibiotic resistance related to biofilm formation in Klebsiella pneumoniae," Pathogens, vol. 3, no. 3, pp. 743-758, 2014.

[26] C. Hennequin, C. Aumeran, F. Robin, O. Traore, and C. Forestier, "Antibiotic resistance and plasmid transfer capacity in biofilm formed with a CTX-M-15-producing Klebsiella pneumoniae isolate," Journal of Antimicrobial Chemotherapy, vol. 67, no. 9, Article ID dks169, pp. 2123-2130, 2012. 


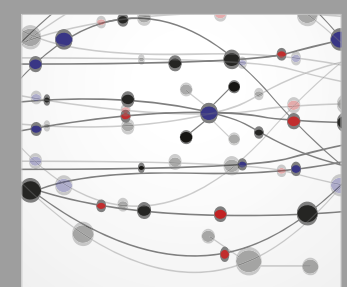

The Scientific World Journal
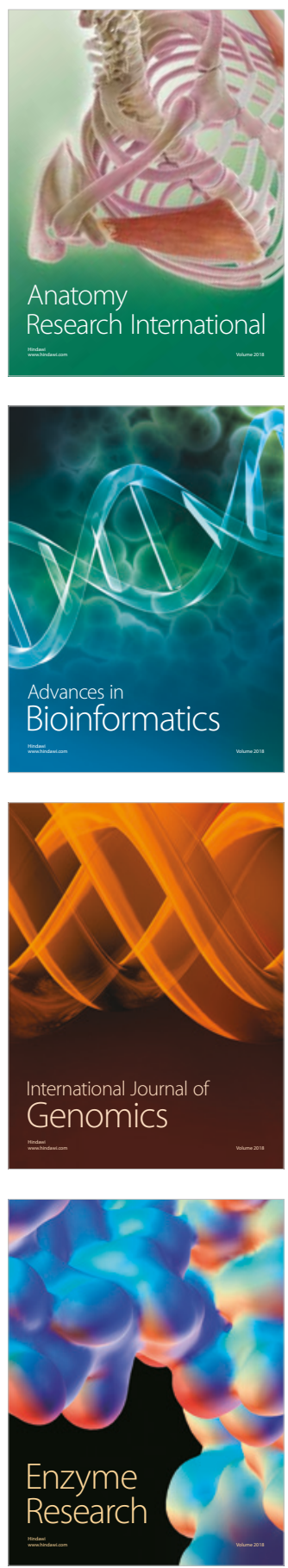
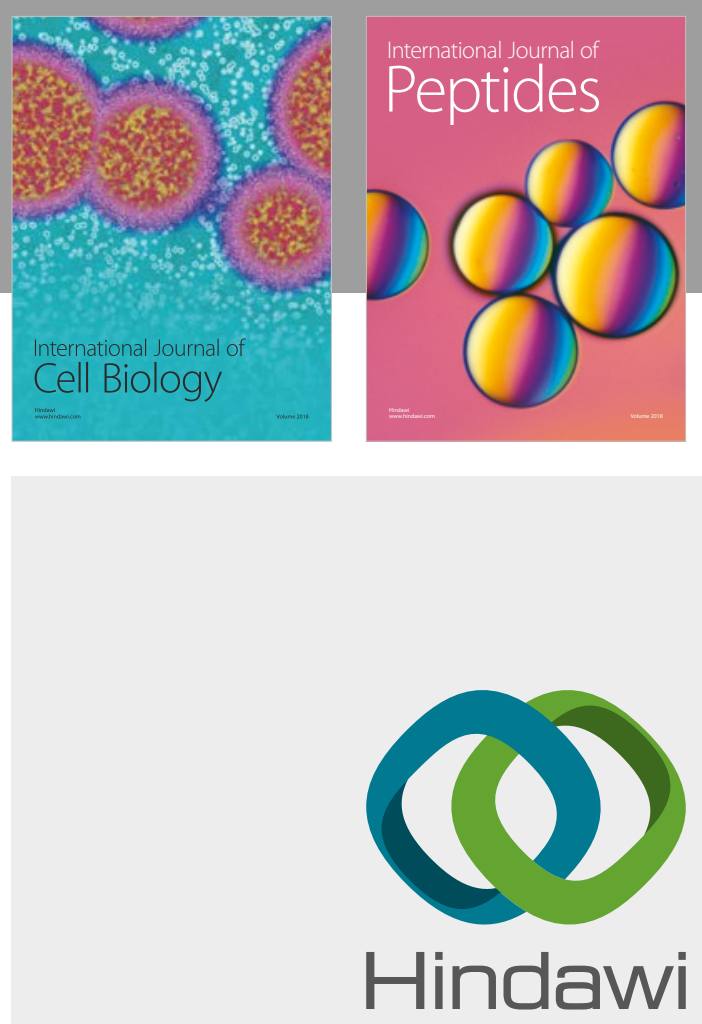

Submit your manuscripts at

www.hindawi.com
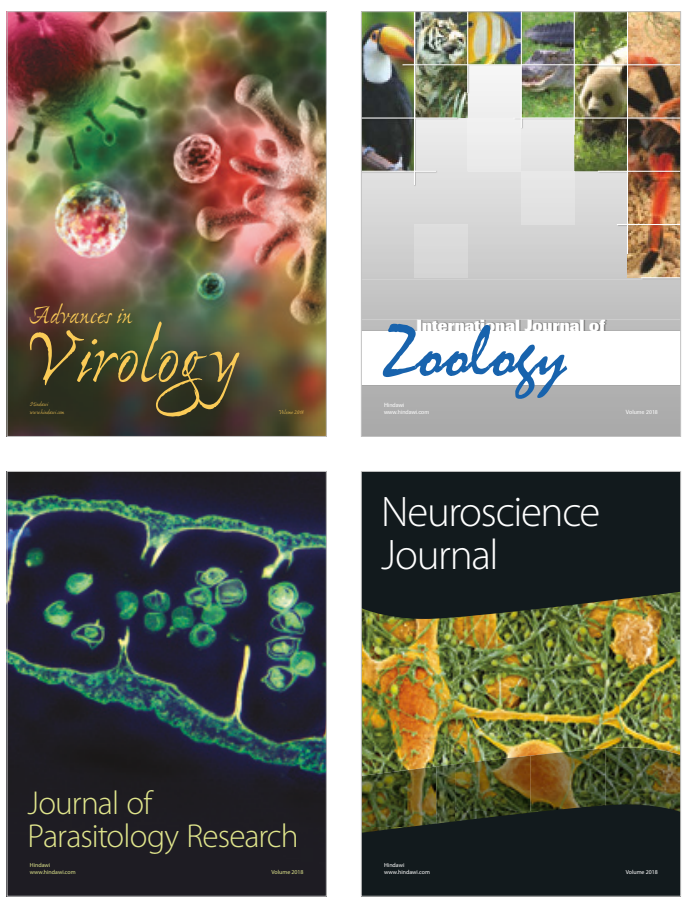
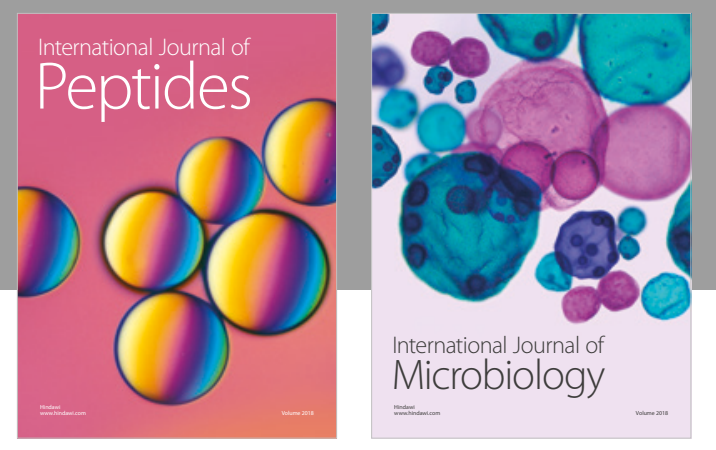

nternational Journal of Microbiology
Journal of
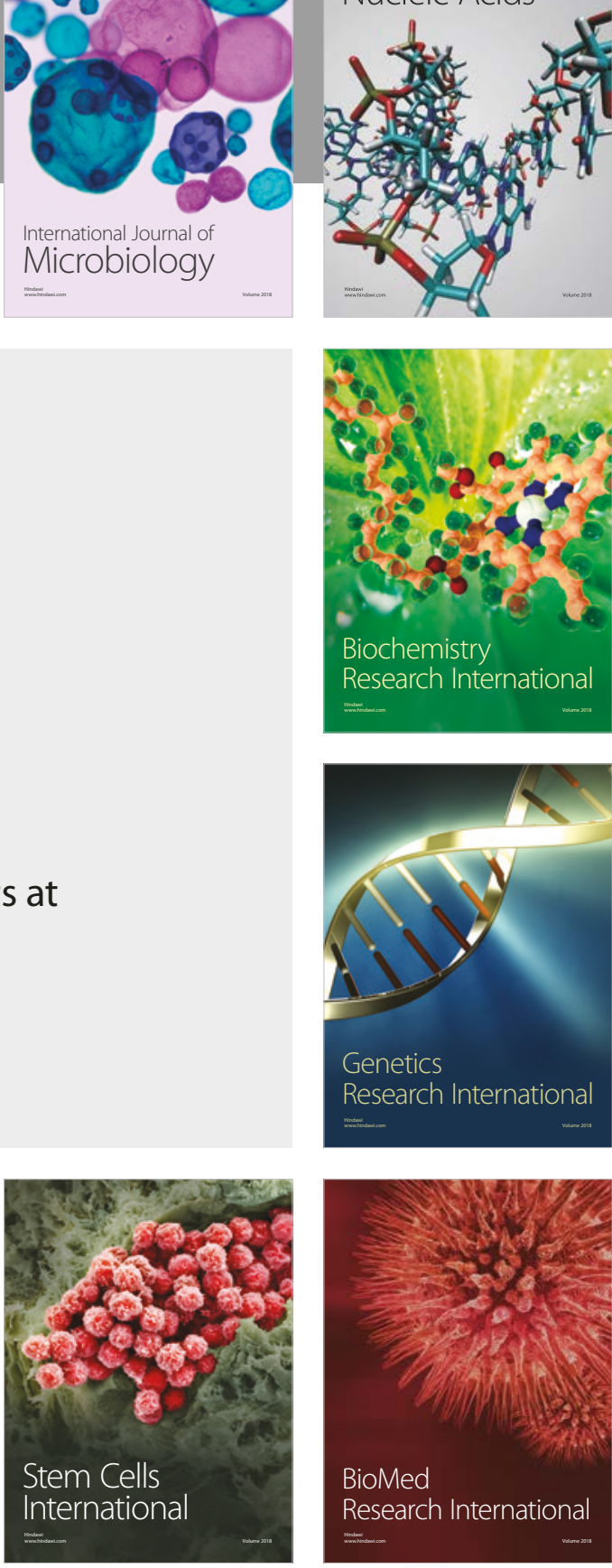
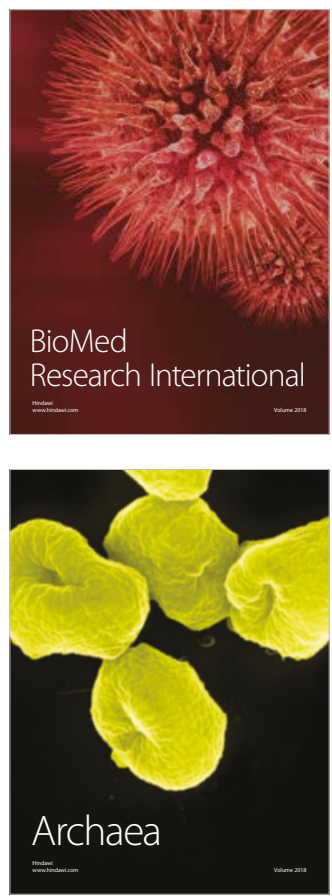